\title{
Metadata of European Lake Fishes Dataset
}

Thomas Mehner (1D, Sandra Brucet, Christine Argillier, Meryem Beklioglu, Teresa Ferreira, Trygve Hesthagen, Kerstin Holmgren, Erik Jeppesen, Fiona Kelly, Teet Krause, Martti Rask, Pietro Volta, Ian J. Winfield \& Samo Podgornik
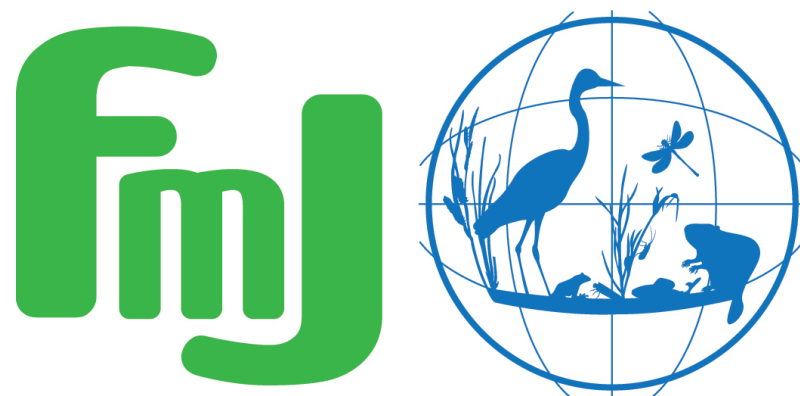

Freshwater Metadata Journal 



\section{Metadata of European Lake Fishes Dataset}

\section{Thomas Mehner ${ }^{1}$ (iD , Sandra Brucet ${ }^{2,3}{ }^{3}$, Christine Argillier ${ }^{4}$, Meryem Beklioglu $^{5}$, Teresa Ferreira $^{6}$, Trygve Hesthagen ${ }^{7}$, Kerstin Holmgren ${ }^{8}$, Erik Jeppesen ${ }^{9}$, Fiona Kelly ${ }^{10}$, Teet Krause ${ }^{11}$, Martti Rask ${ }^{12}$, Pietro Volta ${ }^{13}$, lan J. Winfield ${ }^{14}$ \& Samo Podgornik ${ }^{15}$}

\footnotetext{
1 Leibniz-Institute of Freshwater Ecology and Inland Fisheries, Berlin, Germany; corresponding author: mehner@igb-berlin.de

2 ICREA, Catalan Institution for Research and Advanced Studies, Barcelona, Spain

3 University of Vic - Central University of Catalonia, Vic, Spain

4 Irstea, UR RECOVER, Aix en Provence, France

5 Middle East Technical University, Department of Biological Sciences, Ankara, Turkey

6 University of Lisbon, Instituto Superior de Agronomia, Lisboa, Portugal

7 Norwegian Institute for Nature Reasearch, Trondheim, Norway

8 Swedish University of Agricultural Sciences, Department of Aquatic Resources, Drottningholm, Sweden

9 Department of Bioscience and Arctic Research Centre (ARC), Aarhus, Denmark

10 Inland Fisheries Ireland, Dublin, Ireland

11 Estonian University of Life Sciences, Tartu, Estonia

12 Natural Resources Institute Finland, Jyväskylä, Finland

13 National Research Council, Institute of Ecosystem Study, Verbania Pallanza, Italy

14 Centre for Ecology \& Hydrology, Lancaster, United Kingdom

15 Fisheries Research Institute of Slovenia, Ljubljana, Slovenia
}

Please cite this paper as follows: Mehner, T., Brucet, S., Argillier, C., Beklioglu, M., Ferreira, T., Hesthagen, T., Holmgren, K., Jeppesen, E., Kelly, F., Krause, T., Rask, M., Volta, P., Winfield, I.J. \& Podgornik, S., 2017. Metadata of European Lake Fishes Dataset. Freshwater Metadata Journal 23: 1-8.

https://doi.org/10.15504/fmj.2017.23

Received: 2017-02-27 / Published: 2017-03-09

\section{Keywords}

fish assemblage, species list, Palearctic lakes, multi-mesh gillnet fishing, EU Water Framework Directive

\section{Short description of the dataset/summary}

Here we provide the metadata for an overview on fish species presence/absence in 1943 Palearctic (Europe + Turkey) lakes and reservoirs. The data have been obtained by standardized multi-mesh gillnet fishing, primarily to fulfill the requirements of the European Water Framework Directive (WFD). The species list encompasses about 100 species, a few of them split into subspecies. The database has been accumulated for the purpose of intercalibration of the evaluation systems for the WFD, and has systematically been used for research in the EU project WISER.

\section{General information}

dataset entry ID: $\quad$ FWM_11 


\section{name of the dataset:}

full name of the dataset:

dataset short name:

type of dataset:

data type:
Metadata of European Lake Fishes Dataset

Lake Fish Metadata

species distribution data

point data/observation data

science keywords according to GCMD:

topic: Biosphere, Biological Classification, Climate Indicators

ISO topic category according to ISO 19115:

Biota, Inland Waters

own science keywords:

fish assemblage, lakes and reservoirs, local records, Pan-European coverage

\section{Technical and administrative specifications}

$\begin{array}{ll}\text { data format: } & \text { Excel } \\ \text { operating system: } & \text { all Windows systems } \\ \text { data language: } & \text { English } \\ \text { current access level: } & \text { internal } \\ \quad \text { currently available through GBIF: } & \text { no } \\ \text { exchange planned: } & \text { yes } \\ \text { data in data repository: } & \text { no }\end{array}$

Do you plan to publish the data on the Freshwater Biodiversity Data Portal:

\section{update level: \\ documentation: \\ type: \\ others/details: \\ language:}

\section{contact details:}

metadata contact person:

first, last name:

phone:

email:

institution:

address:

postal code, city:

country

technical contact person:

first, last name:

phone:

email:

scientific contact person:

first, last name:

phone:

email: yes

completed

scientific paper

see dataset related references below

English

Thomas Mehner

+49(0)3064181613

mehner@igb-berlin.de

Leibniz-Institute of Freshwater Ecology and Inland Fisheries Berlin (Germany)

Müggelseedamm 310

12587 Berlin

Germany

Thomas Mehner

+49(0)3064181613

mehner@igb-berlin.de

Thomas Mehner

+49(0)3064181613

mehner@igb-berlin.de 


\section{Intellectual property rights and citation}

dataset creator (data compiler):

contact name:

Thomas Mehner

contact email:

mehner@igb-berlin.de

contact institution:

Leibniz-Institute of Freshwater Ecology and Inland Fisheries Berlin

\section{data contributors to/owners of this dataset:}

number:

multiple

14

data contributor/owner 1:

contact name:

Thomas Mehner

contact email:

mehner@igb-berlin.de

contact institute:

Leibniz Institute of Freshwater Ecology and Inland Fisheries

criteria for using this part of the dataset:

The dataset needs to be requested from dataset creator with specific conditions of use.

data contributor/owner 2:

contact name:

Sandra Brucet

contact email:

sandra.brucet@uvic.cat

contact institute:

ICREA, Catalan Institution for Research and Advanced Studies, Spain

criteria for using this part of the dataset:

The dataset is publicly available (data portal, data archive) and can be used without restrictions, but dataset creator/data contributors must be informed prior to publication. Data must be acknowledged and cited correctly.

data contributor/owner 3:

contact name:

Christine Argillier

contact email:

christine.argillier@irstea.fr

contact institute:

Irstea, UR RECOVER, Aix en Provence, France

criteria for using this part of the dataset:

The dataset needs to be requested from dataset creator with specific conditions of use.

data contributor/owner 4:

contact name:

contact email:

Meryem Beklioglu

contact institute:

meryem@metu.edu.tr

criteria for using this part of the dataset:

The dataset needs to be requested from dataset creator with specific conditions of use.

data contributor/owner 5:

contact name:

contact email:

Teresa Ferreira

contact institute:

terferreira@isa.ulisboa.pt

University of Lisbon, Instituto Superior de Agronomia

criteria for using this part of the dataset:

The dataset needs to be requested from dataset creator with specific conditions of use.

data contributor/owner 6:

contact name:

contact email:

Trygve Hesthagen

contact institute:

trygve.Hesthagen@nina.no

criteria for using this part of the dataset:

The dataset is publicly available (data portal, data archive) and can be used 


\section{data contributor/owner 7:}

contact name:

contact email:

contact institute:

criteria for using this part of the dataset:

\section{Kerstin Holmgren}

kerstin.holmgren@slu.se

Swedish University of Agricultural Sciences, Department of Aquatic Resources

The dataset needs to be requested from dataset creator with specific conditions of use.

\section{data contributor/owner 8:}

contact name:

contact email:

contact institute:

\section{Erik Jeppesen}

ej@bios.au.dk

Department of Bioscience and Arctic Research Centre (ARC), Aarhus

University

criteria for using this part of the dataset:

The dataset needs to be requested from dataset creator with specific conditions of use.

\section{data contributor/owner 9:}
contact name:
Fiona Kelly
contact email:
Fiona.Kelly@fisheriesireland.ie
contact institute:
Inland Fisheries Ireland, Dublin

criteria for using this part of the dataset:

The dataset needs to be requested from dataset creator with specific conditions of use.

\section{data contributor/owner 10:}
contact name:
Teet Krause
contact email:
Teet.Krause@emu.ee
contact institute:
Estonian University of Life Sciences, Tartu
criteria for using this part of the dataset:

The dataset needs to be requested from dataset creator with specific conditions of use.

\section{data contributor/owner 11:}
contact name:
Martti Rask
contact email:
martti.rask@luke.fi
contact institute:
criteria for using this part of the dataset:
Natural Resources Institute Finland, Jyväskylä

The dataset needs to be requested from dataset creator with specific conditions of use.

data contributor/owner 12:

\section{contact name:}

contact email:

contact institute:

criteria for using this part of the dataset:

Pietro Volta

p.volta@ise.cnr.it

National Research Council, Institute of Ecosystem Study, Verbania Pallanza

The dataset needs to be requested from dataset creator with specific conditions of use.

\section{data contributor/owner 13:}
contact name:
contact email:
Ian J. Winfield
ijw@ceh.ac.uk
contact institute:
Centre for Ecology \& Hydrology, Lancaster, U.K.

criteria for using this part of the dataset:
The dataset needs to be requested from dataset creator with specific conditions of use. 


\section{data contributor/owner 14:}

contact name:

contact email:

contact institute:

criteria for using this part of the dataset:

The dataset needs to be requested from dataset creator with specific conditions of use.

\section{citation of this dataset:}

author(s):

title and journal (name, number, pages):

Mehner T., Brucet S., Argillier C., Beklioglu M., Ferreira T., Hesthagen T., Holmgren K., Jeppesen E., Kelly F., Krause T., Rask M., Volta P., Winfield I.J. \& Podgornik S.

European Lake Fish Dataset.

year:

citation of the metadata:

author(s):

title and journal (name, number, pages):

year:

doi:

\section{dataset related references:}

reference 1:

author(s):

title:

year:

doi:

reference 2:

author(s):

title:

year:

doi:

reference 3:

author(s):

title:

year:

doi:

reference 4:

author(s):
Metadata of European Lake Fishes Dataset. Freshwater Metadata Journal 23: $1-8$

2017

Mehner T., Brucet S., Argillier C., Beklioglu M., Ferreira T., Hesthagen T., Holmgren K., Jeppesen E., Kelly F., Krause T., Rask M., Volta P., Winfield I.J. \& Podgornik S.

https://doi.org/10.15504/fmj.2017.23

Brucet, S., Pedron, S., Mehner, T., Lauridsen, T.L., Argillier, C., Winfield, I.J., Volta, P., Emmrich, M., Hesthagen, T., Holmgren, K., Benejam, L., Kelly, F., Krause, T., Palm, A., Rask, M., Jeppesen, E.

Fish diversity in European lakes: geographical predictors dominate over anthropogenic pressures?

2013

https://doi.org/10.1111/fwb.12167

Argillier, C., Caussé, S., Gevrey, M., Pédron, S., De Bortoli, J., Brucet, S., Emmrich, M., Jeppesen, E., Lauridsen, T., Mehner, T., Olin, M., Rask, M., Volta, P., Winfield, I. J., Kelly, F., Krause, T., Palm, A. \& Holmgren, K.

Development of a fish-based index to assess the eutrophication status of European lakes

2013

https://doi.org/10.1007/s10750-012-1282-y

Emmrich, M., Pédron, S., Brucet, S., Winfield, I.J., Jeppesen, E., Volta, P., Argillier, C., Lauridsen, T.L., Holmgren, K., Hesthagen, T. \& Mehner, T.

Geographical patterns in the size structure of European lake fish communities

2014

https://doi.org/10.1111/jbi.12366

Mehner, T., Keeling, C., Emmrich, M., Holmgren, K., Argillier, C., Volta, P., Winfield, I.J. \& Brucet, S. along abiotic and biotic gradients 
title:

year:

doi:

reference 5:

author(s):

title:

year:

doi:

comments:
Effects of fish predation on density and size spectra of prey fish communities in lakes

2016

https://doi.org/10.1139/cjfas-2015-0034

Arranz, I., Mehner, T., Benejam, L., Argillier, C., Holmgren, M., Jeppesen, E., Lauridsen, T.L., Volta, P., Winfield, I.J. \& Brucet, S.

Density-dependent effects as key drivers of intraspecific size structure of six abundant fish species in lakes across Europe

2016

https://doi.org/10.1139/cjfas-2014-0508

Note that the dataset is not publicly available as such.

\section{General data specifications}

regional coverage of the dataset: continents:

Asia, Europe

\section{spatial extent (bounding coordinates):}

southernmost latitude $\left[^{\circ}\right]$ :

36

northernmost latitude $\left[^{\circ}\right]$ :

69

westernmost longitude $\left[{ }^{\circ}\right]$ :

$-10$

easternmost longitude $\left[{ }^{\circ}\right]$ :

minimum altitude:

36

maximum altitude:

0 metres

900 metres

countries:

\section{world climatic regions according to Köppen:}

Europe: Denmark, Estonia, Finland, France, Germany, Ireland, Italy, Norway,

Portugal, Slovenia, Spain, Sweden, United Kingdom

Group C: temperate/mesothermal climates

Group D: continental/microthermal climate

freshwater ecoregions of the world (FEOW) according to WWF:

Europe: Cantabric Coast - Languedoc, Central \& Western Europe, Central

Anatolia, Eastern Iberia, Italian Peninsula \& Islands, Northern Anatolia,

Northern Baltic Drainages, Northern British Isles, Norwegian Sea Drainages,

Southern Baltic Lowlands, Southern Iberia, Upper Danube, Western Anatolia,

Western Caspian Drainages, Western Iberia

\section{European ecoregions according to Illies (WFD):}

Italy, Corsica and Malta (ER3), Alps (ER4), Western Highlands (ER8), Central Highlands (ER9), Western Plains (ER13), Central Plains (ER14), Baltic Province (ER15), Eastern Plains (ER16), Ireland and Northern Ireland (ER17), Great Britain (ER18), Borealic Uplands (ER20), Fenno-Scandian Shield (ER22)

ecosystem type: covered timeframe: comments: lakes/ponds

$1995-2015$

Single survey per lake, no temporal replicates. 


\section{Site specifications}

coordinate system/grid data:

grid data available:

site coding available:

number of sites:

exact number of sites:

\section{Biological data}

biological data origin:

organism group addressed: latitude/longitude, format: DD

no

no

$>1000$

1943

\section{Sample resolution}

\section{fish:}

taxonomic resolution:

level: species

other taxonomic levels: sub-species

percentage of species level data: 100

comments:

from sampling,

standardized multi-mesh gillnet fishing

general compilation,

Intercalibration for European Water Framework Directive, EU project WISER

fish

\section{taxonomic coding:}

taxalist according to:

reference(s):

Resolution primarily on species level; in few cases (e.g., trout), sub-species records are available.

coding system:

Kottelat \& Freyhof

Kottelat, M. \& Freyhof, J. 2007: Handbook of European Freshwater Fishes.

ISBN-13: 9782839902984

none

sample specifications:

specification of method(s) used for sampling and sorting:

Fish sampling in lakes followed the European Standard (CEN 2015: Water quality. Sampling of fish with multi-mesh gillnets. EN 14757. European Committee for Standardization). In short, lakes were fished with benthic multi-mesh gillnets ( $30 \mathrm{~m}$ long, $1.5 \mathrm{~m}$ high, 12 mesh sizes between 5 and $55 \mathrm{~mm}$ in geometric row), the number per lake standardized by lake area and lake depth. Fishing has occurred normally in August or September.

comments: Nomenclature follows primarily Kottelat \& Freyhof.

\section{Other specifications}

GIS layers, shape files related to the dataset:

availability of photos: no data available

availability of maps: no

no

quality control procedures:

Were any quality control procedures applied to your dataset? 
quality control protocols and comments:

Check of correct coordinates by country-specific data owners;

local species lists checked for plausibility by country-specific data owners.

\section{Acknowledgements}

Data compilation has in part been done during the project WISER (Water bodies in Europe: Integrative Systems to assess Ecological status and Recovery) funded by the European Union under the 7th Framework Programme, Theme 6 (Environment including Climate Change, contract No. 226273). The authors wish to thank all Lake Intercalibration experts who contributed to the realisation of the database and, particularly, David Ritterbusch and Uwe Brämick (Germany), Otilia Mihail (Romania) and Robert Rosell (Northern Ireland).

\section{References}

Argillier, C., Caussé, S., Gevrey, M., Pédron, S., De Bortoli, J., Brucet, S., Emmrich, M., Jeppesen, E., Lauridsen, T., Mehner, T., Olin, M., Rask, M., Volta, P., Winfield, I. J., Kelly, F., Krause, T., Palm, A. \& Holmgren, K. , 2013. Development of a fish-based index to assess the eutrophication status of European lakes https://doi.org/10.1007/s10750-012-1282-y

Arranz, I., Mehner, T., Benejam, L., Argillier, C., Holmgren, M., Jeppesen, E., Lauridsen, T.L., Volta, P., Winfield, I.J. \& Brucet, S. , 2016. Density-dependent effects as key drivers of intraspecific size structure of six abundant fish species in lakes across Europe https://doi.org/10.1139/cifas-2014-0508

Brucet, S., Pedron, S., Mehner, T., Lauridsen, T.L., Argillier, C., Winfield, I.J., Volta, P., Emmrich, M., Hesthagen, T., Holmgren, K., Benejam, L., Kelly, F., Krause, T., Palm, A., Rask, M., Jeppesen, E., 2013. Fish diversity in European lakes: geographical predictors dominate over anthropogenic pressures? https://doi.org/10.1111/fwb.12167

Emmrich, M., Pédron, S., Brucet, S., Winfield, I.J., Jeppesen, E., Volta, P., Argillier, C., Lauridsen, T.L., Holmgren, K., Hesthagen, T. \& Mehner, T. , 2014. Geographical patterns in the size structure of European lake fish communities along abiotic and biotic gradients https://doi.org/10.1111/jbi.12366

European Committee for Standardization (CEN), 2015. Water quality. Sampling of fish with multi-mesh gillnets. EN 14757.

Kottelat, M. \& Freyhof, J., 2007. Handbook of European Freshwater Fishes. Publications Kottelat, Cornol and Freyhof, Berlin. ISBN 978-2-8399-0298-4.

Mehner, T., Keeling, C., Emmrich, M., Holmgren, K., Argillier, C., Volta, P., Winfield, I.J. \& Brucet, S. , 2016. Effects of fish predation on density and size spectra of prey fish communities in lakes https://doi.org/10.1139/cjfas-2015-0034 
Appendix 
European lakes with fish data (CCM2, basin level)

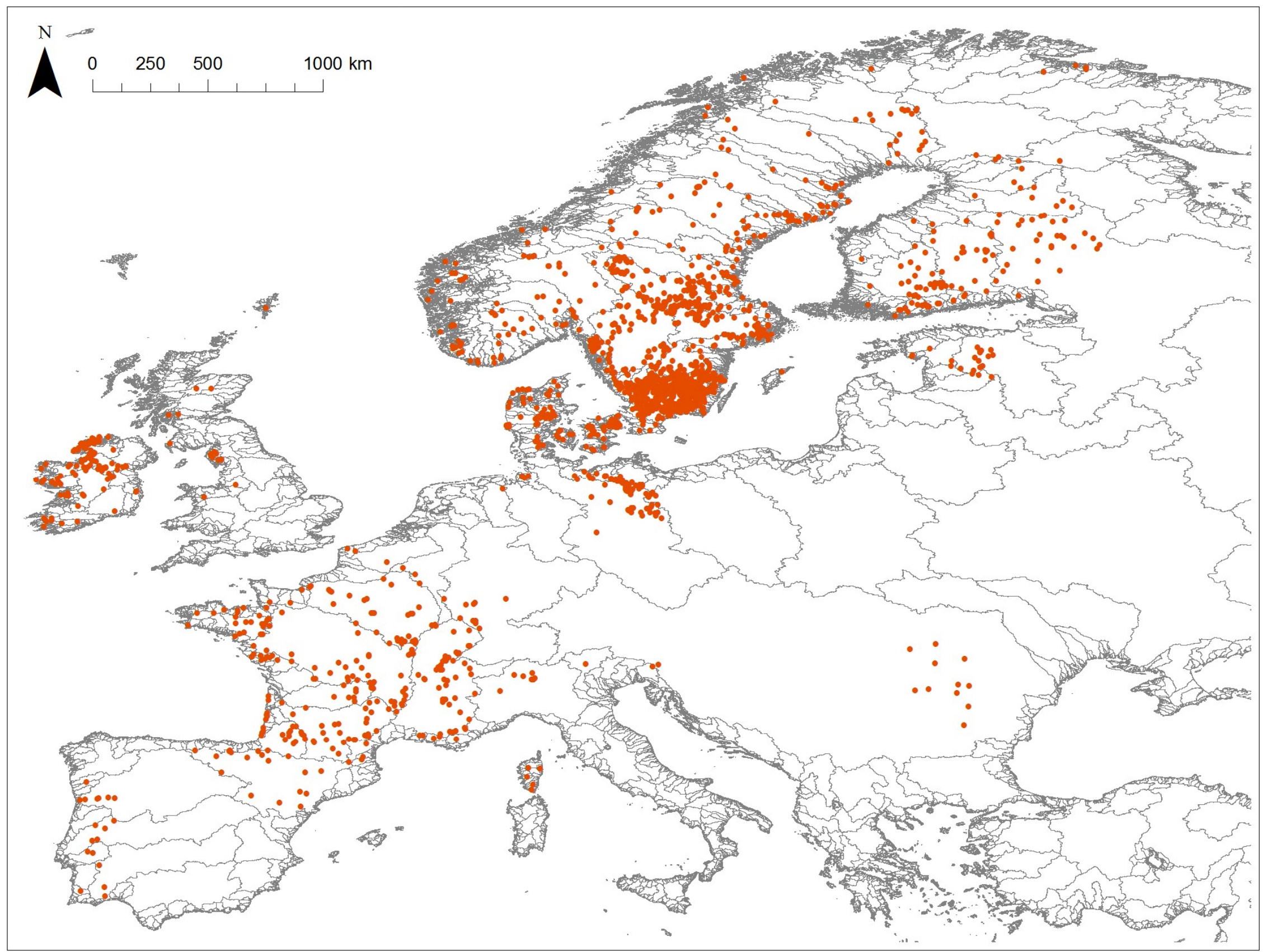

